\title{
Estudo e Monitoramento Tecnológico de Dessalinização via Destilação por Recompressão Mecânica de Vapor
}

\author{
Study and Technological Monitoring of Dessalinization via Distillation \\ by Mechanical Recompression of Steam
}

\author{
Valdirio Alexandre Gadelha Segundo ${ }^{1}$ \\ Mônica Tejo Cavalcanti ${ }^{1}$ \\ José Nilton Silva ${ }^{1}$ \\ ${ }^{1}$ Universidade Federal de Campina Grande, Campina Grande, PB, Brasil
}

\begin{abstract}
Resumo
Este artigo aborda um estudo de monitoramento tecnológico de purificação de águas via destilação por recompressão de vapor, a partir da busca de patentes como fontes de informações. Para levantamento das informações, utilizouse a plataforma Questel Orbit $₫$, aplicando como critério de busca as palavras-chaves "Dessalinização", "Vapor", "Recompressão" e "Mecânica", combinando operadores booleanos e de truncamentos. Foram realizadas análises "macro", "meso" e "micro", com o objetivo de identificar as principais características tecnológicas relacionadas à dessalinização por recompressão de vapor. As aplicações da destilação por recompressão de vapor são amplas e estão em constante desenvolvimento, principalmente nas áreas de recompressão mecânica de vapor e recompressão térmica de vapor. A principal matéria-prima utilizada para a produção foi a água do mar, também denominada de salmoura.
\end{abstract}

Palavras-chave: Dessalinização. Vapor. Recompressão Mecânica.

\begin{abstract}
This article discusses a systematic monitoring study of desalination by distillation through vapor recompression using patents as information source. In order to collect that information, it was used as tool the Questel Orbit ${ }^{\circledR}$ platform, applying the keywords "Desalination", "Vapor", "Recompression", and "Mechanical", combining Boolean and truncation operators. Macro-, Meso-, and Microanalysis were carried out with objective of identifying the main technological characteristics related to desalination by distillation through vapor recompression. The applications of the vapor recompression distillation are extensive and are in constant development, mainly in the areas of mechanical recompression of vapor and thermal recompression of steam. The main raw material used for the production was seawater, as known as brine.
\end{abstract}

Keywords: Desalination. Vapor. Recompression. Mechanical.

Área Tecnológica: Tecnologia Ambiental. 


\section{Introdução}

O tratamento e purificação da água é um tema secular. A humanidade busca constantemente desenvolver tecnologias cada vez mais eficientes para obtenção de água tratada e purificada, associada à viabilidade socioeconômico. Entre as diversas tecnologias, pode-se dividir em processos físicos e processos físico-químicos. Nos processos de tratamento e purificação de águas, a intenção é reduzir e/ou remover contaminantes como sólidos suspensos, orgânicos biodegradáveis, orgânicos voláteis, patogênicos, orgânicos refratários, nutrientes nitrogenados e fosforados, metais pesados, sais e sólidos dissolvidos orgânicos. Cada classe de contaminantes pode ser removida por diferentes operações e diferentes tecnologias (SILVEIRA et al., 2015).

A aplicação da tecnologia dependerá do tipo de água e da finalidade do seu uso. Entre os tipos e a finalidade do uso da água, é possível destacar estes: água potável para consumo humano, água ultrapura e água de reuso para processos industriais. A água potável, regulamentada pela Portaria n. 2.914 do Ministério da Saúde (BRASIL, 2011), diz respeito ao uso direto e indireto para o consumo humano, além do uso para agricultura e agropecuária.

A água ultrapura é utilizada para fins específicos, em que a qualidade da água pode interferir no processo e nos procedimentos, como: processos industriais, hospitais e laboratórios. Por sua vez, a água de reuso, também pode ser utilizada na indústria, no entanto, com recomendação para limpezas, jardinagem, carreador de resíduos orgânicos e umectação de vias.

Entre as tecnologias de tratamento e de purificação estão os processos que usam filtração por membranas. As membranas são utilizadas para separar substâncias solúveis e insolúveis de águas residuais a partir da atuação de uma força que direciona o líquido a passar por uma membrana semipermeável. O uso de membranas nos processos pode ser classificado em função do tamanho das partículas que será separada, a saber: microfiltração, com retenção de partículas de até 0,1 micron; ultrafiltração (0,01 micron); nanofiltração (0,001 micron); e osmose inversa (0,0001 micron).

Além dos processos por membranas, há os processos térmicos, sendo um deles a tecnologia de purificação por Destilação por Compressão de Vapor (DCV). Além desse, outros processos podem ser citados, como: flash de múltiplo estágio, destilação por meio de energia solar e ebulição de efeitos múltiplos. Por sua vez, o princípio de purificação de água pela tecnologia DCV está no uso da compressão do vapor, em que duas câmaras são conectadas por área de troca térmica contribuindo para a evaporação da água. O compressor cria um vácuo na câmara primária, direcionando o vapor para compressão na câmara secundária, condensando-o e transferindo calor para a câmara primária. Silveira et al. (2015) descrevem o arranjo DCMV como uma destilação onde o vapor é comprimido mecanicamente através de um compressor, elétrico ou a diesel.

Um estudo de monitoramento tecnológico faz parte do estudo de Prospecção Tecnológica, ou forecast (ing), foresight (ing) ou future studies, que permite fornecer informações e indicações das principais tendências tecnológicas no contexto mundial (PORTER, 2004). Esses estudos auxiliam a identificação do estado da técnica de tecnologias e suas tendências e desenvolvimento tecnológicos, alinhado com as necessidades da sociedade. A sistematização da prática de monitoramento tecnológico consiste em coletar, analisar informações sobre os desenvolvimentos científicos e tecnológicos, em uma dada área de interesse, para dar suporte em uma ação ou decisão. 
A busca em documentos de patentes permite gerar informações de apoio ao levantamento do estado da técnica da tecnologia de dessalinização via destilação por recompressão mecânica de vapor. A partir do estado da técnica, tem-se a possibilidade de identificar os estágios e a relevância das tecnologias, tendência para surgimento de novas tecnologias, investimentos, processos, produtos, PD\&I, fusões e aquisições, parceiros, concorrentes no mercado, dentre outras.

\subsection{Dessalinização via DCMV}

O arranjo DCMV tem como base um processo de destilação em que o vapor é comprimido mecanicamente por meio de um compressor e pode ser utilizado para dessalinização. O vapor comprimido é usado como fonte de calor adicional para realizar a vaporização do efluente de entrada, mais especificamente salmoura. O vapor quente oriundo da unidade de evaporação é utilizado como fonte de energia, que será transferido do vaso externo para a própria unidade de evaporação. A descrição do sistema é representada pela Figura 1.

Figura 1 - Arranjo de destilação por recompressão mecânica de vapor (DCMV) para um processo de dessalinização

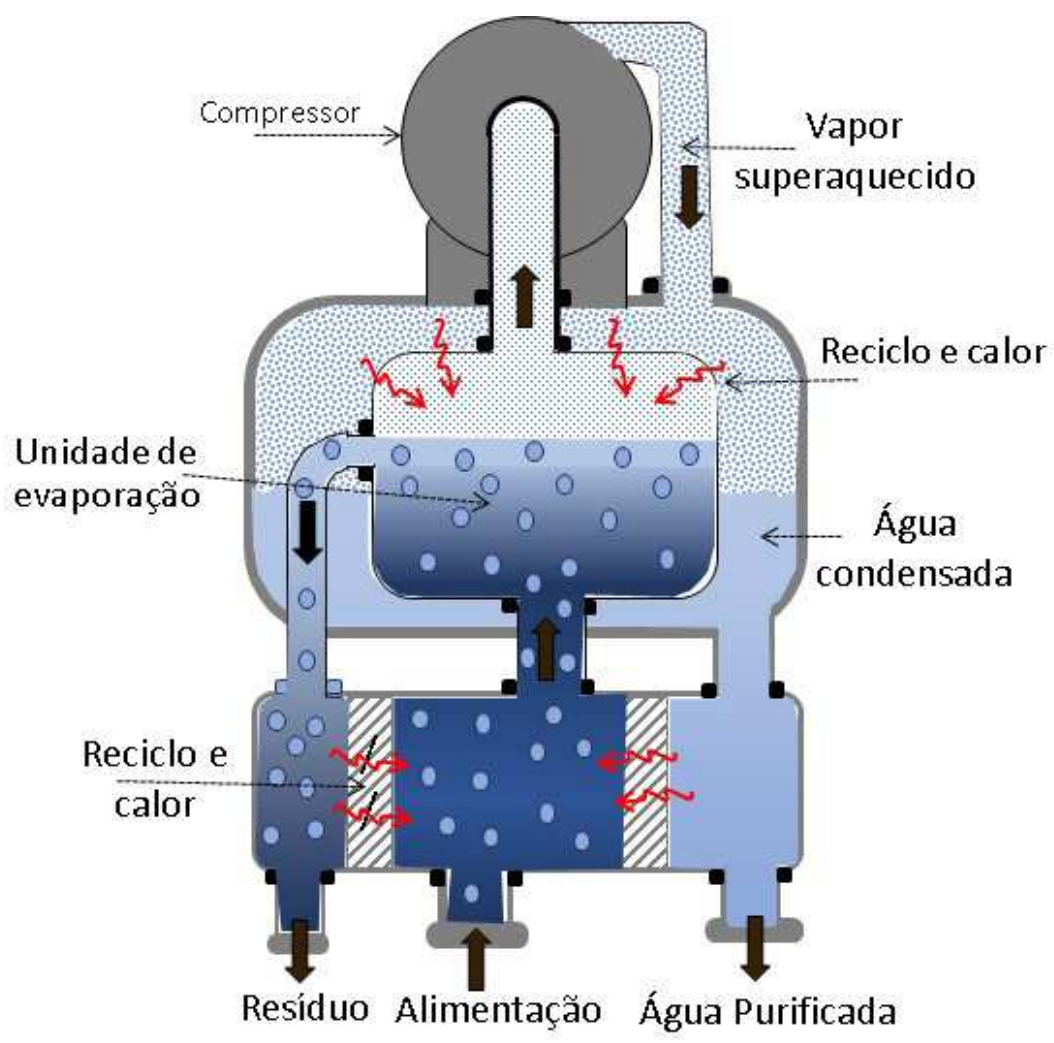

Fonte: Adaptada de Kamen e Demers (2003)

A purificação de água por Destilação por Compressão de Vapor (DCV) é um processo termomecânico. Como pode ser observado na Figura 2, o princípio de purificação de água pela tecnologia DCV está no uso da compressão do vapor que é realizada pelo compressor, já que duas câmaras de evaporação e de condensação são conectadas por área de troca térmica (A), contribuindo para o aumento da taxa de evaporação da água. O compressor cria um vácuo na câmara primária (4), direcionando o vapor para compressão na câmara secundária, condensando-o e transferindo calor para a câmara primária. 
Figura 2 - Fundamento do sistema de Destilação por Compressão de Vapor

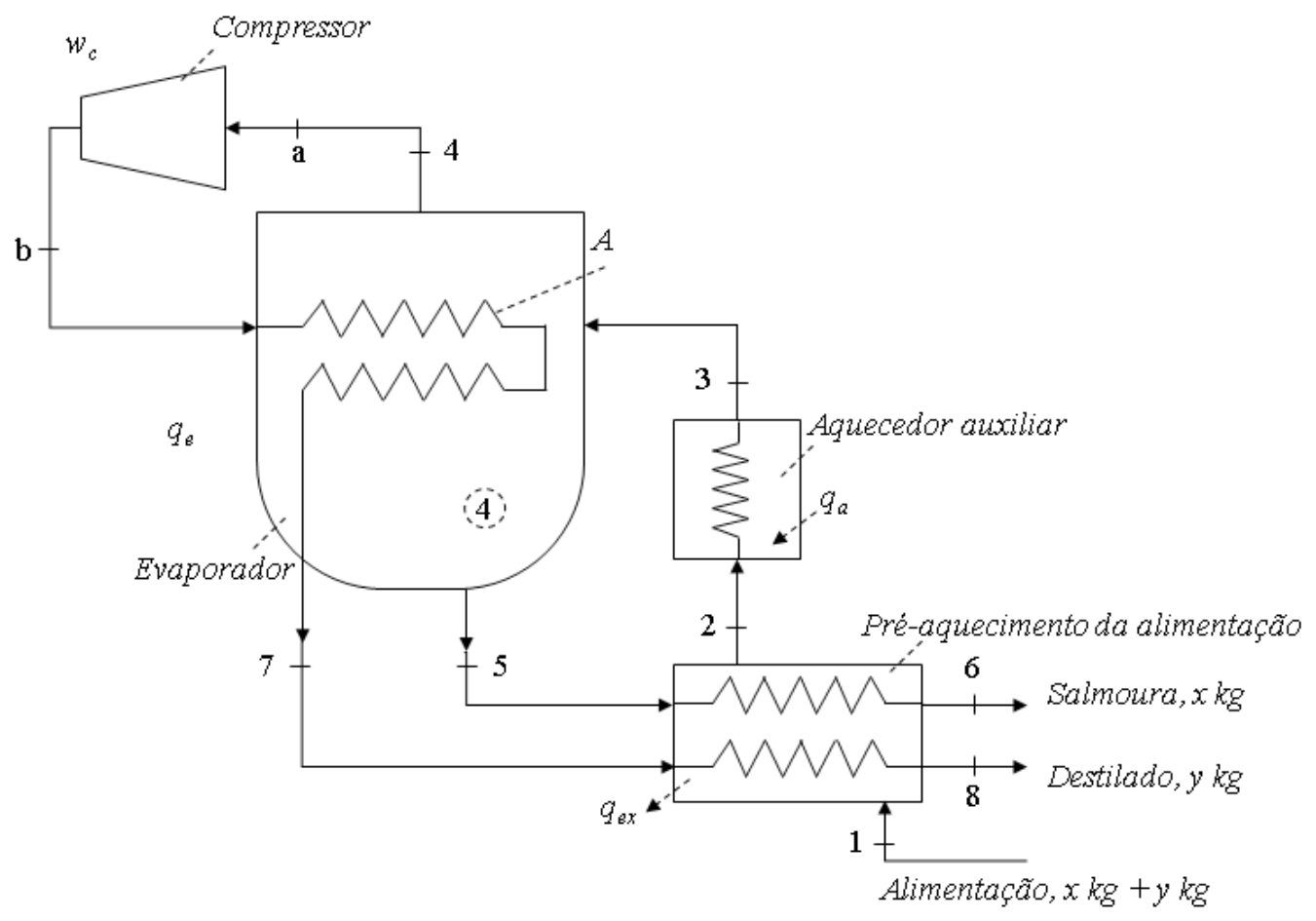

Fonte: Adaptada de Tleimat (2010)

Ainda com relação à Figura 2, a água de alimentação é adicionada e pré-aquecida pelas correntes de saída, passando por um aquecedor auxiliar (3), que serve para realizar o primeiro aquecimento, sendo utilizado apenas para correção energética de funcionamento de partida do processo. Na câmara de evaporação (4), a pressão é reduzida devido ao funcionamento do compressor, pois a água passa a ter maior pressão de vapor (b), o que facilitará a evaporação da água. Com a sucção do vapor de água, após o compressor, a água estará em uma região de maior pressão, fazendo com que condense, e o calor gerado seja liberado na câmara, seguindo como água purificada. Além disso, será gerada uma água residual, por isso, então, estudos indicam um aproveitamento de até 98 \% da água de alimentação, um valor significativo de aproveitamento da água a ser purificada.

Por meio da compressão de vapor realizada pelo compressor, ocorre a separação entre água e resíduos orgânicos ou inorgânicos presentes em solução ou suspensão. Tal compressão aspira parte da água do interior da primeira câmara e transfere para a segunda câmara. Estudos comprovam que a tecnologia DCV pode ser utilizada para purificação de águas contendo sais, e águas provenientes de efluentes, permitindo um maior aproveitamento hídrico (ALY; EL-FIQI, 2003; BAHAR; HAWLADER; WOEI, 2004; JAICHANDER; NAYAR; LIENHARD, 2016).

\subsection{Objetivos}

O objetivo deste estudo é realizar o levantamento do estado da técnica atual das tecnologias de dessalinização via Destilação por Compressão Mecânica de Vapor (DCMV) a partir da aplicação sistemática do monitoramento de patentes para verificação do desenvolvimento tecnológico utilizando a plataforma Questel Orbit ${ }^{\circledR}$. 


\section{Metodologia}

O método de monitoramento tecnológico realizado neste estudo consistiu na utilização de informações oriundas de documentos de patentes com intuito de mapear tecnologias no contexto da dessalinização via destilação por compressão/recompressão mecânica de vapor, utilizando como principal ferramenta de busca a plataforma Questel Orbit $\AA$.

O levantamento de informações de tecnologias de dessalinização foi realizado a partir do uso da palavra-chave "Dessalinização" como entrada para a ferramenta Questel Orbit ${ }^{\circledR}$, nos campos título, resumo e palavras-chave, de forma a obter o maior número representativo de documentos entre 1998 e 2018; obtendo, assim, o primeiro elemento da análise Macro, contendo 10.887 patentes depositadas. Com o objetivo de restringir a pesquisa, foram utilizadas as palavras-chaves "Recompressão" e "Vapor". Após a análise de 160 documentos considerados relevantes para o estudo, analisou-se detalhadamente o total de 51 patentes. A leitura dos documentos de patentes foi feita com o intuito de extrair informações em três níveis diferentes, a saber: Macro, Meso e Micro.

A análise no nível Macro consistiu em uma análise dos documentos de acordo com a série histórica de patentes concedidas, a distribuição por países, por universidades, centros de pesquisa e por empresas ligadas ao conhecimento científico e ao desenvolvimento da tecnologia e de parcerias (internacionais e com empresas).

$\mathrm{Na}$ análise nível Meso, os documentos foram categorizados de acordo com os aspectos mais relevantes em torno da dessalinização via destilação por compressão/recompressão de vapor, considerando as seguintes taxonomias:

a) Processo e tecnologia: quando são identificados nos documentos etapas e tecnologias da dessalinização por recompressão de vapor.

b) Matéria-prima: quando são identificadas nos documentos as principais matérias-primas integrantes do processo de dessalinização por recompressão de vapor.

c) Equipamento: quando se identifica o equipamento responsável pelo processo de dessalinização por recompressão de vapor.

Por fim, como análise nível Micro, foram identificadas as particularidades e os detalhamentos de cada taxonomia da análise Meso, dessa maneira, restringiu-se a busca para o tema específico, denominado dessalinização via destilação por recompressão mecânica de vapor.

\section{Resultados e Discussão}

Após a realização das buscas e de leitura do conteúdo dos documentos de patentes selecionados a partir da metodologia aplicada, as informações extraídas foram analisadas nos três níveis de análise.

\subsection{Distribuição de Patentes}

A primeira análise está relacionada com a evolução da produção tecnológica que se refere a tecnologias de dessalinização em número de patentes concedidas por ano. É possível observar 
com base nos dados da Figura 3 que nos anos 1998 a 2018 houve uma quantidade significativa de documentos de interesse em torno do tema "Dessalinização", mais precisamente 10.731 patentes concedidas.

Em especial, destaca-se o período entre 2013 e 2017, que somados o número de patentes concedidas representa $50 \%$ do total de patentes em 20 anos. $\mathrm{O}$ ano com maior número de patentes concedidas foi 2016 com 1.406 patentes, totalizando $13 \%$.

Figura 3 - Número de Patentes Concedidas por Ano

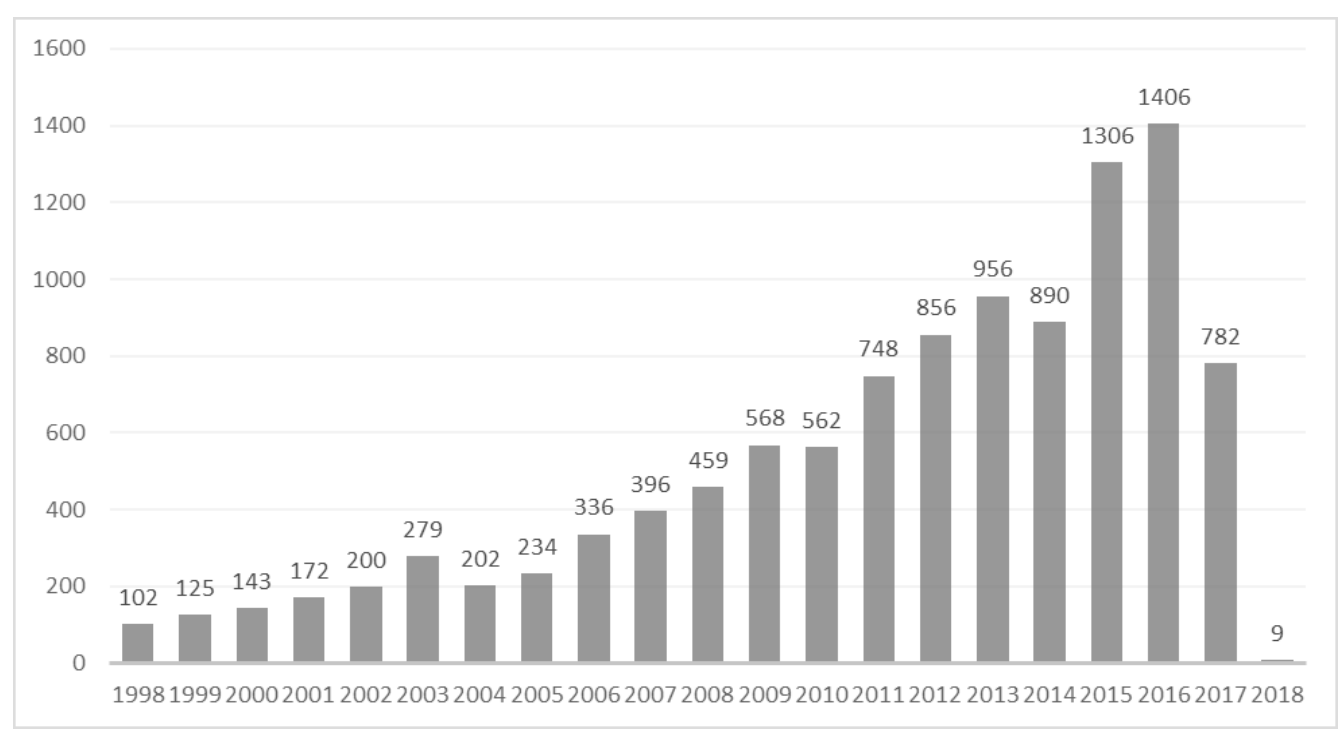

Fonte: Elaborada pelos autores deste artigo com base no Questel Orbit ${ }^{\circledR}(2018)$

As instituições que desenvolvem tecnologias relacionadas à dessalinização foram classificadas em empresas e universidades/centros de pesquisas. Essa distribuição está representada na Figura 4.

Figura 4 - Empresas e Universidades/Centros de Pesquisa que desenvolvem tecnologias relacionadas ao tema

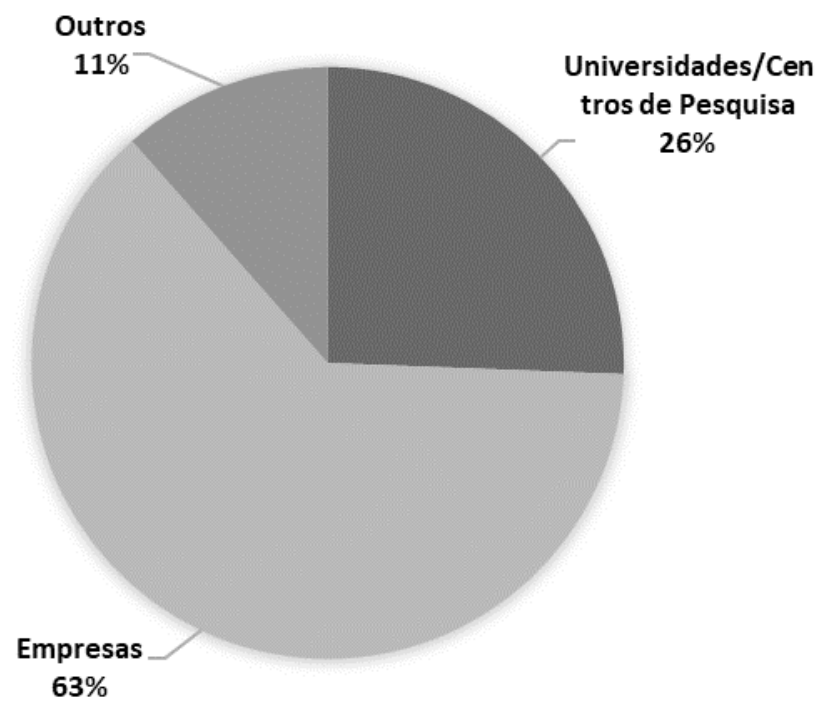

Fonte: Elaborada pelos autores deste artigo com base no Questel Orbit ${ }^{\circledR}(2018)$ 
Dos dados relacionados à Figura 4, destacam-se a Hitachi como a empresa com maior número de patentes e a Tianjin University como a instituição de ensino com maior número de patentes. Esses dados estão dispostos na Figura 5 com seus respectivos quantitativos percentuais.

Figura 5 - Distribuição percentual de Empresas e Universidades/Centros de Pesquisa com maior número de patentes

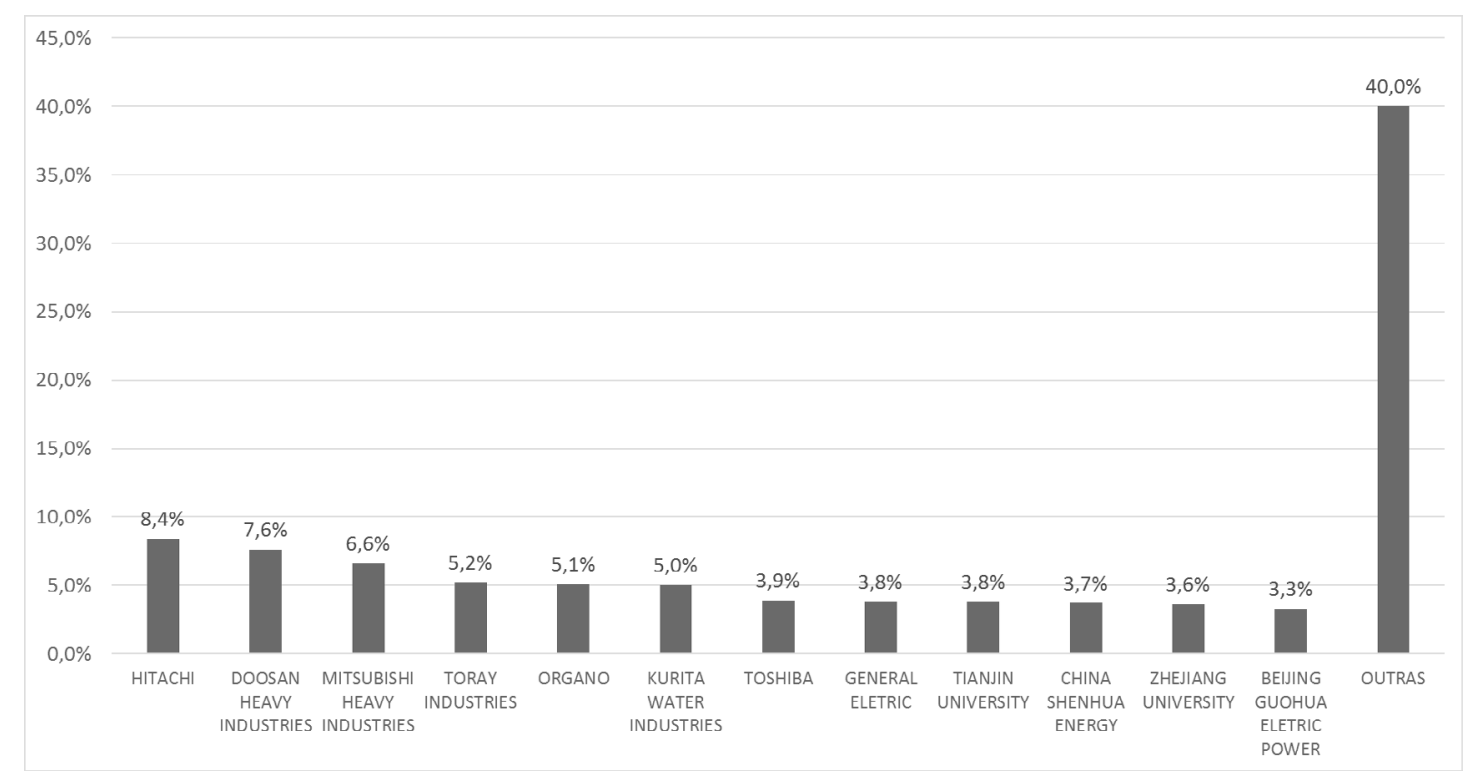

Fonte: Elaborada pelos autores deste artigo com base no Questel Orbit ${ }^{\circledR}(2018)$

Na Tabela 1 estão descritas as principais universidades ou centros de pesquisa que estão relacionados com dessalinização, com mais de 500 patentes publicadas. Para essa tabela, foram selecionadas as 10 universidades com o maior número de patentes publicadas.

Tabela 1 - Número de Patentes das Principais Universidades e Centros de Pesquisa

$\begin{array}{cc}\text { Principais Universidades E Centros de Pesquisa } & \begin{array}{c}\text { Número DE } \\ \text { Publicaçóes }\end{array} \\ \text { Tianjin University } & 58 \\ \text { Zhejiang University } & 55 \\ \text { Korea Institute of Energy Research } & 40 \\ \text { Dalian University of Technology } & 39 \\ \text { Hohai University } & 39 \\ \text { Zhejiang Ocean University } & 37 \\ \text { Jiangnan University } & 36 \\ \text { Korea Institute of Machinery \& Materials } & 32 \\ \text { Shenhua Guohua Beijing Eletric Power Research Institute } & 31 \\ \text { Beijing University of Technology } & 30\end{array}$

Fonte: Elaborada pelos autores deste artigo com base no Questel Orbit® (2018)

Em relação aos países de origem das patentes, a China se destaca com $47 \%$ do total de número de patentes depositadas sobre dessalinização. Tal destaque se deve ao fato de menos de 
$60 \%$ das tecnologias serem nacionais em 2011 , havendo um objetivo de aumentar esse número para 90\% até 2020 (WINES, 2011). Na Figura 6 percebe-se que a China lidera com grande margem em relação ao segundo país com maior número de patentes concedidas, a Coreia do Sul, sendo que a diferença fica próxima dos $40 \%$.

Figura 6 - Distribuição percentual de patentes concedidas por país

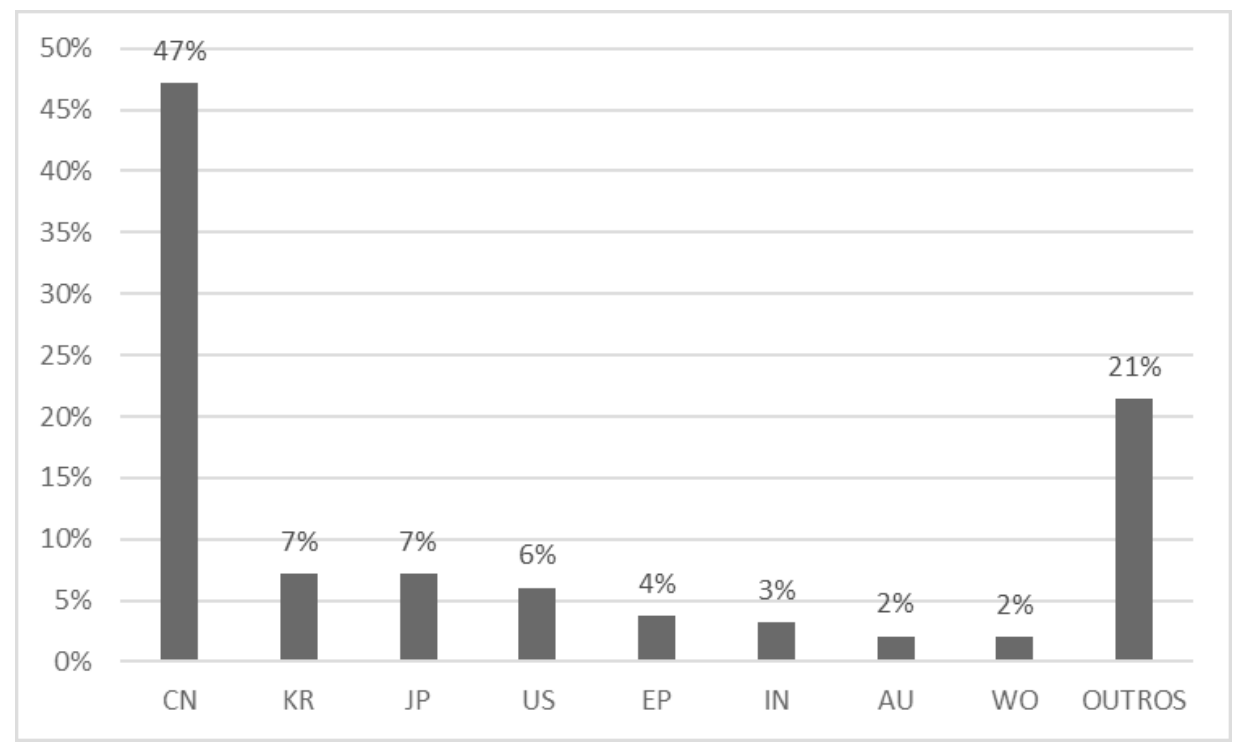

Fonte: Elaborada pelos autores deste artigo com base no Questel Orbit ${ }^{\circledR}$ (2018)

\subsection{Características Tecnológicas}

De acordo com a distribuição de patentes por domínio tecnológico, constata-se que a dessalinização está contida em diversos domínios, como mostra a Figura 7, sendo que a maior parte está contida no domínio chamado tecnologia ambiental, num total de $41,5 \%$ das patentes. Em seguida, o domínio engenharia química representa $21,5 \%$ das patentes em relação ao domínio tecnológico. Somados, os dois domínios tecnológicos representam $63 \%$ de todas as patentes.

Figura 7 - Distribuição de Patentes por domínio tecnológico

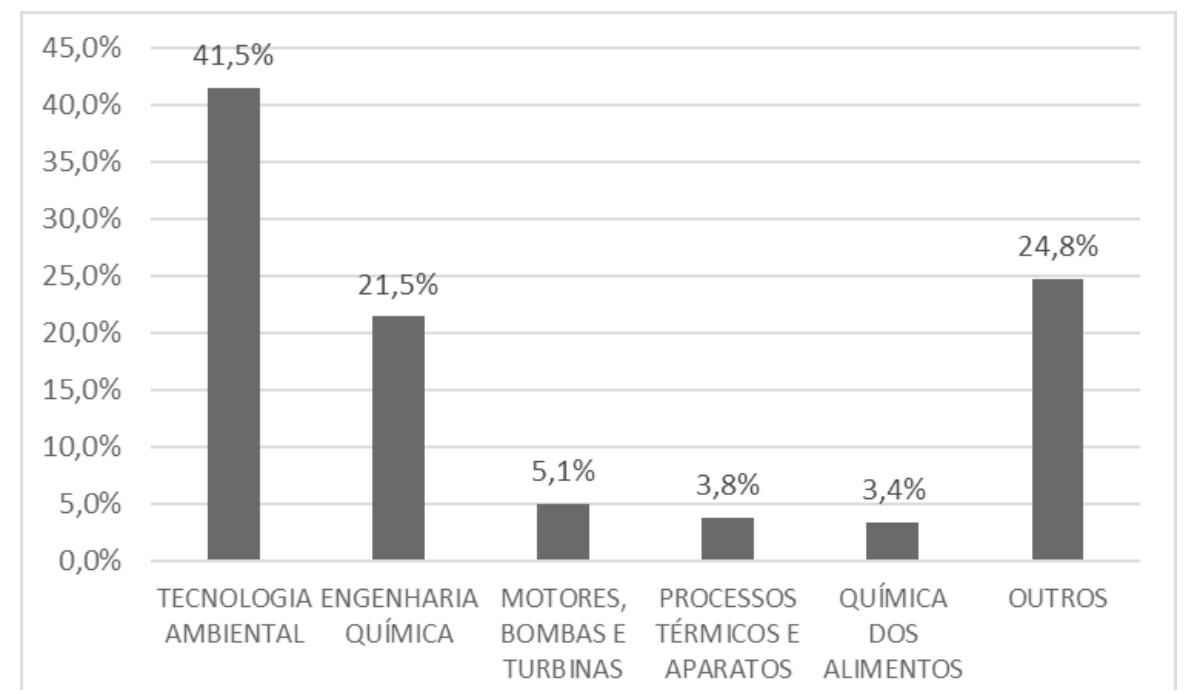

Fonte: Elaborada pelos autores deste artigo com base no Questel Orbit ${ }^{\circledR}(2018)$ 
Para a análise "meso", foram pesquisadas palavras-chave que restringissem a pesquisa, voltando-a aos domínios tecnológicos e aos processos, às matérias-primas e aos equipamentos. As palavras-chave dessalinização, recompressão e vapor, combinadas aos operadores booleanos e de truncamento, trouxeram resultados relevantes para a análise Meso. Ao total, foram encontradas 170 resultados, e 160 deles compõem o total de patentes concedidas de 1998 a 2018, como pode ser observado na Figura 8.

Figura 8 - Distribuição de Patentes para Dessalinização por Recompressão de Vapor

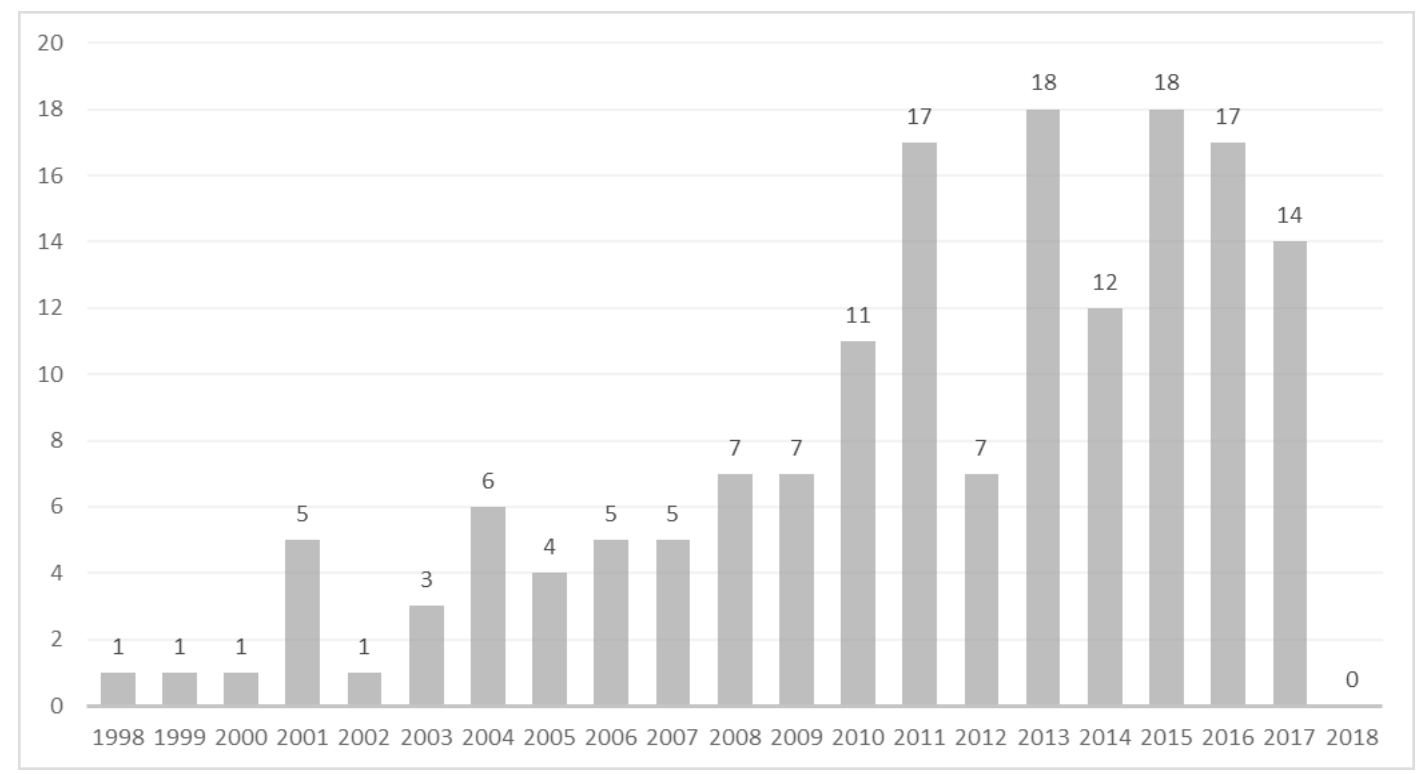

Fonte: Elaborada pelos autores deste artigo com base no Questel Orbit ${ }^{\circledR}(2018)$

Foram identificadas por meio da pesquisa a partir de palavras-chave seis áreas tecnológicas relevantes relacionadas à dessalinização via destilação por compressão/recompressão de vapor e a distribuição por número de patentes, como mostra a Figura 9. Sobre os resultados obtidos por meio da plataforma Questel Orbit ${ }^{\circledR}$, pode-se destacar, em número de patentes, a área "dessalinização de água do mar".

Figura 9 - Áreas Tecnológicas Relevantes

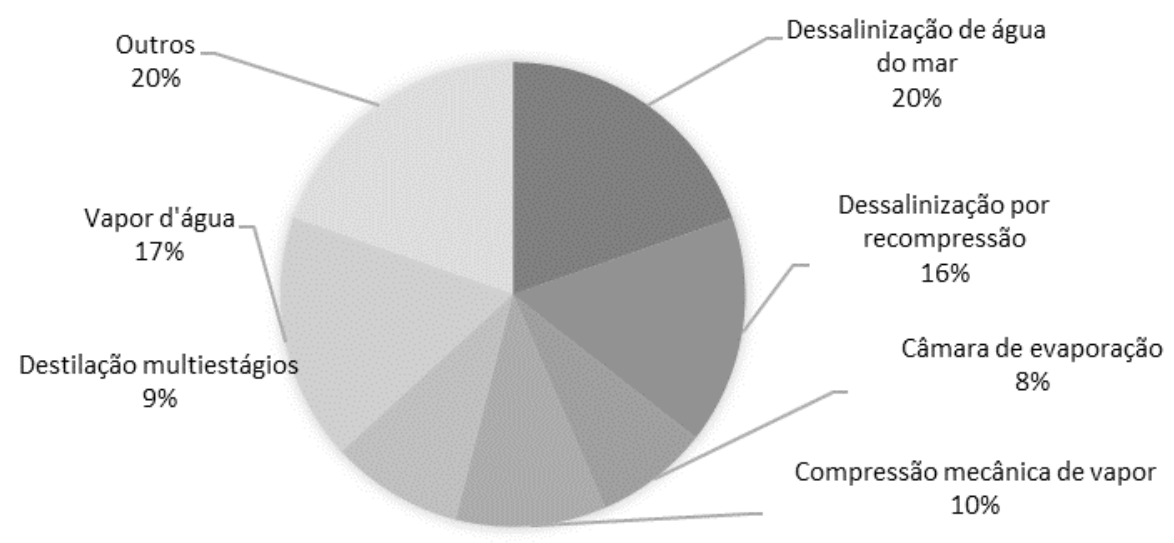

Fonte: Elaborada pelos autores deste artigo com base no Questel Orbit ${ }^{\circledR}(2018)$ 
A área de dessalinização está relacionada ao processo e à tecnologia capaz de promover a separação da salmoura em água pura e salmoura concentrada. Por sua vez, a água do mar se encaixa como a matéria-prima utilizada no processo de separação. Nessa matéria-prima foram encontradas duas tecnologias capazes de promover a separação por recompressão de vapor: a dessalinização por recompressão mecânica de vapor e a dessalinização por recompressão térmica de vapor. Nesse caso, a área "Câmara de Evaporação" está relacionada ao equipamento utilizado para que ocorra a destilação por recompressão de vapor. O motivo pelo qual a área "Dessalinização de água do mar" está em maior porcentagem relaciona-se diretamente ao fato de as áreas que abrangem matéria-prima e equipamento estarem contidas no processo de dessalinização.

Após a análise das tecnologias e processos, das matérias-primas e dos equipamentos, foi realizada a leitura dos títulos e dos resumos com a finalidade de filtrar patentes que estivessem diretamente relacionadas aos arranjos DCV, aplicado à dessalinização. A partir dessa filtragem, selecionou-se 30 patentes que serviram de base para o estudo da dessalinização por recompressão mecânica de vapor e 21 patentes que serviram de base para o estudo da dessalinização por recompressão térmica de vapor. Além disso, duas patentes englobavam ambos os arranjos. Portanto, pode-se observar a distribuição de patentes relacionadas ao tema na Figura 10.

Figura 10 - Distribuição das Patentes Relacionadas ao tema Dessalinização por Recompressão de Vapor

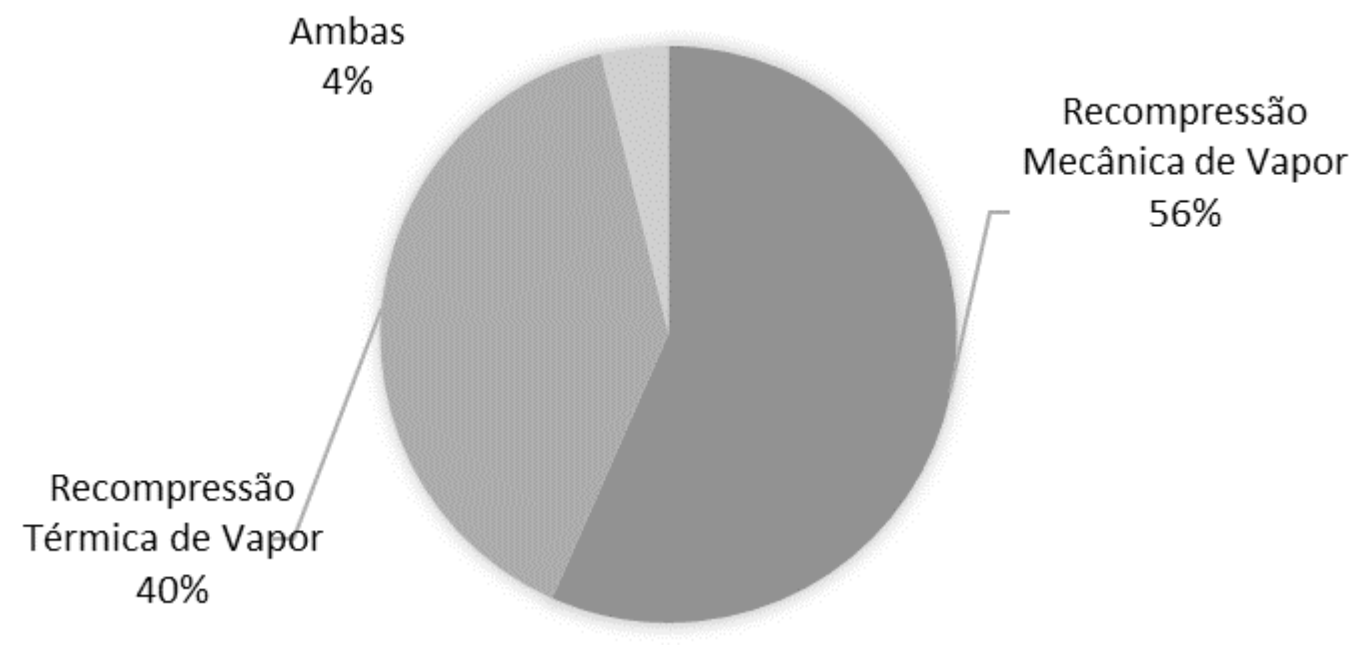

Fonte: Elaborada pelos autores deste artigo com base no Questel Orbit ${ }^{\circledR}(2018)$

A Figura 10 apresenta a distribuição das patentes relacionadas à dessalinização por destilação via recompressão mecânica de vapor após a seleção que utilizou-se das palavras-chave dessalinização, Recompressão, Mecânica e Vapor. É possível observar que o ano de 2015 teve o maior número de registros, sete, por motivos provavelmente relacionados àqueles da Tabela 1. 
Figura 11 - Distribuição Específica das Patentes Relacionadas à Destilação por Recompressão Mecânica de Vapor

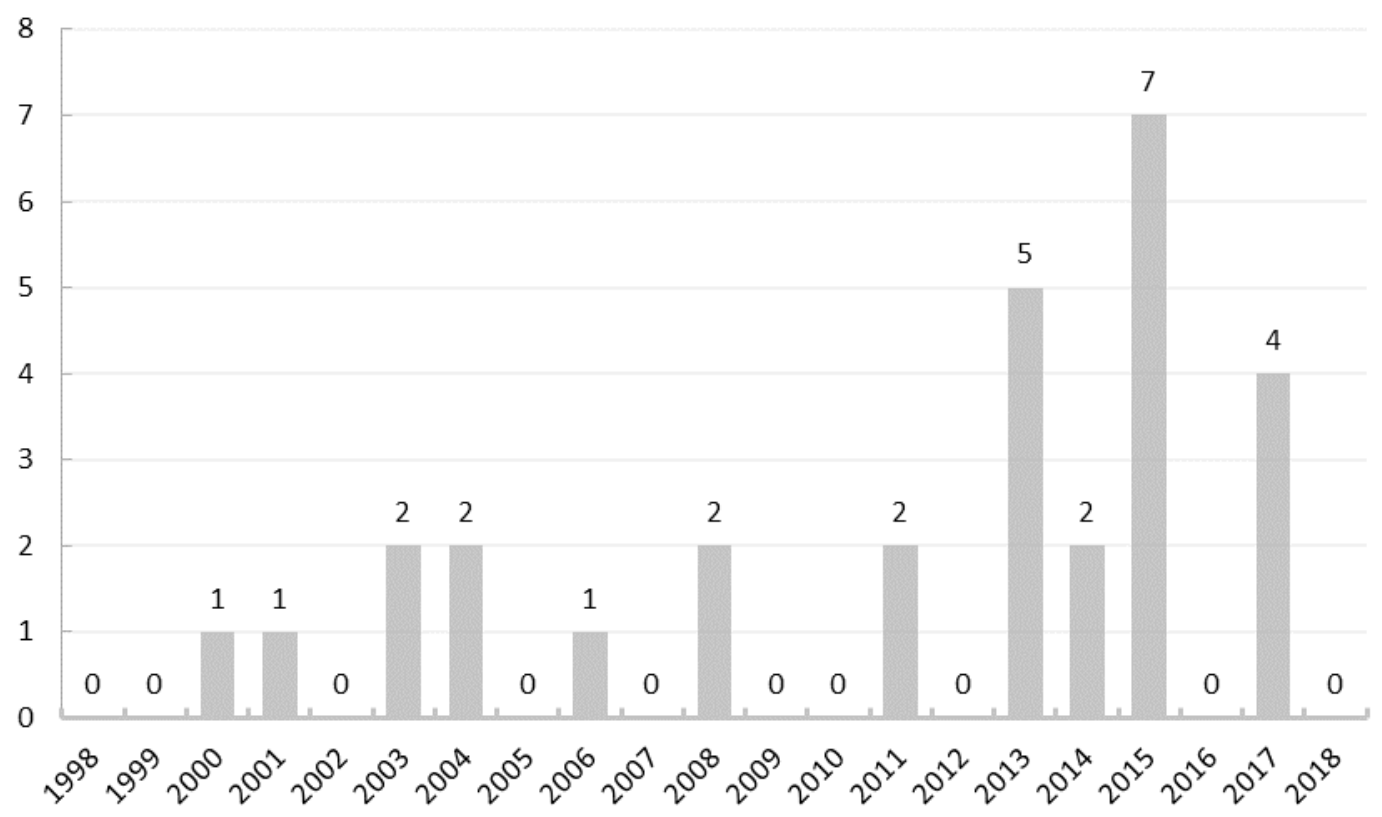

Fonte: Elaborada pelos autores deste artigo com base no Questel Orbit ${ }^{\circledR}(2018)$

\section{Considerações Finais}

A partir do estudo das patentes publicadas entre os anos de 1998 a 2018, pode se obter algumas conclusões. Analisando os depósitos por ano, pode-se verificar que houve um aumento gradual do número de tecnologias criadas, relacionadas com a dessalinização, e o ano 2016 apresentou o maior número depósitos de patentes, totalizando 1.406 depósitos de patentes, equivalente a $13 \%$ do total.

Em relação aos países, observa-se que a China aparece em destaque no número de depósito de patentes. Por sua vez, empresas tiveram o maior número de depósitos, totalizando $63 \%$ do total de depósitos de patentes.

Entre as tecnologias relacionadas à dessalinização via destilação por compressão de vapor, as que mais se destacaram foram: compressão mecânica de vapor com 56\%; e compressão térmica de vapor com $40 \%$.

As aplicações da destilação por recompressão de vapor são amplas e estão em constante desenvolvimento, principalmente nas áreas de recompressão mecânica de vapor e recompressão térmica de vapor.

A principal matéria-prima utilizada para a produção foi a água do mar, também denominada de salmoura.

Em relação ao processo de dessalinização via destilação por recompressão mecânica de vapor, destaca-se o ano de 2015 com sete patentes. 


\section{Referências}

ALY, N. H. Aly; EL-FIQI, A. K. El-Fiqi. Mechanical vapor compression desalination systems: a case study. Desalination, [S.l.], v. 158, p. 143-150. 2003.

BAHAR, R.; HAWLADER, M. N. A.; WOEI, L. S. Performance evaluation of a mechanical vapor compression desalination system. Desalination, [S.1.], v. 166, p. 123-127. 2004.

BRASIL, Ministério da Saúde. Portaria n. 2.914, de 12 de dezembro de 2011. Dispõe sobre normas de potabilidade de água para o consumo humano. Brasília, DF: SVS, 2011.

JAICHANDER, S.; NAYAR, K. G.; LIENHARD, J. H. V. Mechanical Vapor compressio-Membrane Distillation Hybrids for Reduced Specific Energy Consumption. Desalination and Water

Treatment, [S.l.], v. 57, n. 55, p. 26.507-26.517, 2016.

KAMEN, D.; DEMERS, J. A. Locally Powered Water Distillation Dystem. United States Patente Application Pulication, n. 2004/0159536, DEKA Products Limeted Partnership, Manchester, NH, 2003.

PORTER, Alan L. et al. Technology futures analysis: towards integration of the field and new methods. Technological Forecasting and Social Change, [S.l.], n. 49, 2004.

SILVEIRA, A. P. P. et al. Dessalinização de Águas. [S.l.]: Oficina de Textos. 2015. p. 288.

TLEIMAT, B.; Mechanical Vapor Compression Distillation. Water Re-use Technology, Alamo, California, USA Thermal Desalination Processes - Vol. II - Mechanical Vapor Compression Distillation - Encyclopedia of Desalination and Water Resources (DESWARE), Ed. International Editorial Board. 2010.

WINES, M. China Takes a Loss to Get Ahead in the Business of Fresh Water. The New York Times, 2011. Disponível em: <https://www.nytimes.com/2011/10/26/world/asia/china-takes-loss-to-getahead-in-desalination-industry.html> . Acesso em: 26 jul. 2018.

\section{Sobre os autores}

\section{Valdirio Alexandre Gadelha Segundo}

E-mail: valdirio.segundo@eq.ufcg.edu.br Mestrando em Engenharia Química pela Universidade Federal de Campina Grande, desde 2018. Graduando em Engenharia Química pela Universidade Federal de Campina Grande, desde 2008.

Endereço profissional: Universidade Federal de Campina Grande, Centro de Ciências e Tecnologia, Unidade Acadêmica de Engenharia Química - UAEQ, Laboratório Integrado de Engenharia e Processo - LIEP. Rua Aprígio Veloso, n. 882, Universitário, Bloco CX, Campina Grande, PB. CEP: 58429-900.

\section{Mônica Tejo Cavalcanti}

E-mail:monicatejoc@yahoo.com.br

Doutora em Engenharia de Processos pela Universidade Federal de Campina Grande (2011). Mestre em Ciência e Tecnologia de Alimentos na área de Química e Bioquímica de Alimentos pela Universidade Federal da Paraíba (2007).

Endereço profissional: Universidade Federal de Campina Grande, Centro de Ciências e Tecnologia, Centro de Ciências e Tecnologia Agroalimentar (UATA). Rua Jairo Vieira Feitosa, s/n, Bairro dos Pereiros, Pombal, PB. CEP: 58840-000. 


\section{José Nilton Silva}

E-mail: nilton@eq.ufcg.edu.br

Professor Adjunto da Universidade Federal de Campina Grande, lotado no Departamento de Engenharia Química.

Endereço profissional: Universidade Federal de Campina Grande, Unidade Acadêmica de Engenharia Química,

Bloco CM. Rua Aprígio Veloso, n. 882, Universitário, Bloco CX, Campina Grande, PB. CEP: 58429-900. 